\title{
Música y violencia de género en España. Estudio comparado por estilos musicales
}

Music and gender violence in Spain. A comparative study by musical styles

\author{
Jaime Hormigos-Ruiz / jaime.hormigos@urjc.es \\ http://orcid.org/0000-0002-9728-2256 \\ María Gómez-Escarda / maria.gomez@urjc.es \\ http://orcid.org/0000-0002-2785-7077 \\ Salvador Perelló-Oliver / salvador.perello@urjc.es \\ http://orcid.org/0000-0003-2655-440X \\ Universidad Rey Juan Carlos de Madrid, España
}

\begin{abstract}
Violence against women remains a first-order social problem in contemporary societies. The objective of this work is to study how this problem is treated in popular music songs in Spain, establishing a relationship between the different musical styles and the description they make of gender violence. This research is developed from a quantitative methodology based on the content analysis of a sample of 210 songs that deal with gender violence in their lyrics over the last 40 years. This research wants to show how popular music songs are an ideal communication tool to raise awareness of the dimensions of the problem of gender violence.
\end{abstract}

Key words: violence against women, songs, sociology of music, musical communication, socialization.

Resumen: La violencia contra las mujeres continúa siendo un problema de primer orden en las sociedades contemporáneas. El objetivo de este trabajo es estudiar cómo se trata dicho problema en las canciones de música popular en España, estableciendo una relación entre los diferentes estilos musicales y la descripción que hacen de la violencia de género. Para ello, se ha optado por desarrollar una metodología cuantitativa basada en el análisis de contenido de una muestra integrada por un total de 210 canciones, las cuales poseen esta temática, acumuladas a lo largo de las últimas cuatro décadas. La presente investigación pretende mostrar cómo las canciones de música popular pueden ser una herramienta de comunicación ideal para concienciar a la sociedad sobre las dimensiones del problema de la violencia de género.

Palabras clave: violencia contra las mujeres, canciones, sociología de la música, comunicación musical, socialización. 


\section{Introducción}

La música es un sistema de transmisión de información sumamente eficiente por su extraordinaria capacidad para quedar grabada en la memoria. De acuerdo con los estudios de Ramírez (2006), podemos afirmar que las canciones son instrumentos mnemotécnicos muy efectivos para almacenar el saber de una sociedad y, por tanto, para utilizarlas en el proceso de socialización del individuo. En las canciones, la música nos aporta el sentimiento y la emoción, mientras que el texto aporta el aspecto cognitivo (Giménez, 1997: 93). Aplicadas al estudio de la violencia de género, pueden ser una herramienta útil para conocer cómo percibe la sociedad este problema, ya que permiten acceder a la visión de la realidad de un grupo y al conocimiento de su entorno (Carballo, 2006: 32).

Según los planteamientos de Small (2003), las canciones nos pueden transmitir sentimientos y emociones que toman significado en mensajes que se interpretan en un contexto comunicativo dado. Estudiando la forma como se perciben estas canciones, podremos comprender mejor los mecanismos que dotan de significado el lenguaje musical de una determinada sociedad, porque los textos de las canciones van cargados de valores sociales. De este modo, si vivimos en una sociedad sexista, esto quedará reflejado, para bien o para mal, en sus formas artísticas.

La comunicación a través de la música sólo existe mediante la relación particular que se establece entre el "oído social"; es decir, la forma en la que la sociedad dota de carga cognitiva y sensorial a los mensajes que recibe de los sonidos, y la "puesta en escena". En nuestra sociedad es habitual escuchar canciones de música popular donde los roles de hombre y mujer quedan muy delimitados en torno a estereotipos culturalmente aprendidos.

Levitin (2014) y Lynskey (2016) afirman que las canciones surgen de lo que nos rodea y son arquetípicas, ponen música a lo que captan los sentidos y, de este modo, dan testimonio de los problemas que rodean a los individuos. Además, no son productos muertos atados a un tiempo y un lugar concreto, sino organismos cambiantes que toman forma con cada escucha. Sus letras van mucho más allá de las modas y convenciones, siempre estarán en permanente circulación en el imaginario colectivo (Romero, 2011: 37).

Las composiciones que contienen letras que versan sobre la violencia de género, tanto las que fomentan este tipo de violencia como las que critican dichos comportamientos, quedarán grabadas en la memoria sonora de nuestra sociedad y se utilizarán en cada contexto donde suenan de distinto modo; de tal manera que la puesta en escena de estas canciones terminará matizando 
la importancia que la sociedad dé a su mensaje. Abren una ventana a través de la cual podemos percibir el mundo que nos rodea, comunicando ideas que facilitan la creación de valores sociales compartidos; por eso son tan eficaces para educar y sensibilizar a la sociedad sobre determinados problemas (Giménez, 1997; Gallardo y Estévez, 2014).

Desde esta perspectiva, podemos trabajar con las canciones que tratan la violencia de género en sus textos como un instrumento de comunicación que muestre a la sociedad las dimensiones actuales de esta problemática.

\section{Conocer la realidad a través de las canciones}

A la hora de analizar la composición de las canciones se debe tener en cuenta que si bien no todas son artísticamente valiosas, sí tienen un componente comunicativo esencial determinado por las preferencias y la forma de escuchar que está presente en un tipo de sociedad y que se ha ido construyendo a lo largo del tiempo (Hormigos, 2008: 189).

De acuerdo con los estudios de Alcalde (2007: 23), se puede afirmar que las canciones se componen con la idea de establecer una relación con referentes culturales y se destinan intencionalmente a conmover a los individuos que forman parte de una sociedad. Así, podemos comprobar que el tratamiento de la violencia de género en las letras ha ido variando a lo largo de las décadas, en función de la toma de conciencia que se ha producido sobre esta problemática.

La particularidad comunicativa que posee la estructura de una canción es que comprime el significado y lo transmite con menos palabras de las que se utilizarían en una conversación. Esta situación genera, en muchos casos, ambigüedad. Dicha ambigüedad llama a la participación e invita a quien escucha a convertirse en intérprete activo. Los estilos musicales en los cuales se enmarcan las canciones que denuncian la violencia de género son, en muchos casos, fundamentales para que un individuo interprete el mensaje.

Si los estilos musicales son poco seguidos es posible que se pierda la importancia del mensaje; mientras que si los estilos están de moda, el mensaje llegará con más fuerza. Las canciones que nos rodean nacen de la preocupación, el enojo, la duda y, casi siempre, de la emoción (Lynskey, 2016: 12). Generan en los oyentes imágenes sonoras coherentes a través de las cuales se aprecia una forma particular de entender los problemas de la sociedad, que variará dependiendo de la configuración del contexto donde se escucha.

Por ejemplo, hay canciones que hablan de la violencia de género que hoy se censuran; pero en la época cuando se compusieron fueron grandes éxitos, 
precisamente por el mensaje que transmitían. De este modo, se puede escuchar la misma canción una y otra vez matizando el significado final que se percibe.

Para Drösser (2012), esta percepción se llevará a cabo con base en los patrones culturales reiterados que marca la estructura social en cada momento. La repetición de un ritmo, de una temática, de expresiones concretas, etcétera, es algo esperado por el oído musical cuando se expone a las canciones, ya que ahí se busca un sentimiento de identidad entre la temática de la que habla la canción, la sociedad donde queda inmersa esa temática, el intérprete y el público que finalmente la recibe (Hormigos, 2010).

El lenguaje de las canciones que, a priori, se presenta excesivamente sencillo y no articulado lingüísticamente, sirve para crear una herramienta idónea que muestra temas de interés social desde una perspectiva mucho más abierta que la que proporcionaría el lenguaje hablado. Por eso entendemos que el lenguaje es una herramienta útil para mostrar el tratamiento de la violencia de género en nuestra sociedad. Las canciones tienen una función educadora fundamental, porque actúan directamente sobre nuestra opinión.

Romero (2011: 30) explica que la memoria sonora de los individuos genera un sinfín de relaciones con la psique, establecidas con base en impactos emocionales. A lo largo de la vida, dichos impactos van creando un almacén de sonidos formado de experiencias propias y códigos culturales heredados al que se recurre a la hora de exponernos a los distintos tipos de música que nos rodean. Por ejemplo, si a un niño se le expone continuamente, como forma de ocio, a estilos musicales y canciones donde se menosprecia continuamente el rol social de la mujer, estará más predispuesto a reconocer valores positivos en la violencia de género.

Por otra parte, Ramírez (2006: 132) afirma que, en muchos casos, cuando nuestra cultura musical crea canciones no busca tanto la composición perfecta, sino manifestar una idea que llegue con fuerza al individuo que la escucha. En este sentido, la misión de las canciones de protesta que censuran la violencia de género no consiste en dar la vuelta al mundo, sino en cambiar opiniones y perspectivas, en decir algo sobre los tiempos que nos ha tocado vivir $y$, a veces, en descubrir que lo que se dice remite también a otros momentos de la historia (Lynskey, 2016: 11).

Para comprender el mensaje comunicativo de una canción no basta sólo con escucharla y entender su temática, es necesario conocer también el contexto social al que representa y del cual se sirve para adquirir sentido (Alcalde, 2007: 115). En el caso de la violencia de género, es fundamental entender la relación entre la temática de las canciones y la puesta en escena que determina la sociedad; pues el mensaje estará mediado por los parámetros propios del 
saber cultural, el estado de conciencia que tenga el individuo sobre el tema y el gusto por el estilo que ordena el discurso musical (Buil y Hormigos, 2016: 63). Por mucho que se utilicen las canciones para combatir la violencia de género, si la sociedad ofrece a esos estilos musicales un lugar eminentemente periférico en la distribución de esos contenidos, el mensaje no llegará con la fuerza suficiente para denunciar situaciones y cambiar actitudes.

Las canciones se pueden disfrutar de muchas formas: como música de fondo, como objetos estéticos carentes de significado concreto, como música para cantar y bailar acompañando a diversas manifestaciones festivas, etcétera (Levitin, 2014: 53). De este modo, en la escucha de las canciones intervienen dos dimensiones: lo que se puede oír realizando una simple escucha y lo que no se oye de primeras, pero que el tema sí nos muestra. Más allá del significado aparente que nos transmita la letra, se puede reconocer una intencionalidad que aporta al tema un significado mucho más profundo.

A una canción que llega a nosotros se le puede atribuir un significado estandarizado con base en modelos de interpretación aprendidos. Se presentará como algo inocente ligado al ámbito de la diversión, como herramienta para el baile o como ruido de fondo que nos acompaña en las tareas diarias. Pero, además, se puede analizar la canción con el fin de buscar un significado más profundo.

En ese caso, la canción se convierte en un potente medio de comunicación capaz de entrar en el análisis de cualquier cuestión social y educar al individuo sobre la respuesta que debe dar a esa situación. En este sentido, podemos entender determinados estilos musicales que en nuestra sociedad se destinan al baile y a la diversión, como por ejemplo el reguetón, como músicas inocentes que sirven para evadirse de la realidad, o analizarlas como sonidos que fomentan de una manera directa la violencia de género.

La modalidad de escucha condiciona la percepción de una canción y nos muestra el interés que el público proyecta en la temática tratada y en el estilo musical que rodea al mensaje que se quiere transmitir. Por tanto, a la hora de analizar la violencia de género a través de las letras de las canciones debemos fijarnos en el tipo de escucha que realiza el individuo, quien se expone a ese tema. Solemos utilizar dos tipos distintos de escucha que no son excluyentes (Alcalde, 2007).

En primer lugar, la escucha simple, la cual consiste en un acercamiento primario, confortable y acrítico a la temática de la canción donde interviene más el gusto por un estilo de música concreto que la percepción real del mensaje. En este caso, nos fijamos poco en el significado e interpretamos con base en un discurso aprendido de la experiencia social. Nos llama más el envoltorio 
que acompaña al mensaje (ritmo, intérprete, puesta en escena, entre otros aspectos), que el mensaje en sí.

Para este caso, lo que da sentido a la canción es una respuesta del oyente, la cual queda condicionada por modelos de reacción aprendidos en su cultura y que provocan que todas las canciones con algún parecido rítmico sean objeto de una aceptación e interpretación similar. Para los intereses comerciales es más útil crear un significado en la canción a partir de esta escucha subjetiva que condiciona nuestra respuesta menos enérgica al identificarnos menos con el tema de la canción, lo cual posibilita, como veremos en el análisis, una distribución masiva de este tipo de canciones.

En segundo lugar, la escucha atenta parte de la idea de que las canciones, en muchos casos, comunican algo más que la mera forma y los significados derivados de usos y etiquetas culturales; comunican una forma de sentir propia de un determinado grupo social. Por tanto, a la hora de realizar este tipo de escucha se busca asociar el texto de la canción al contexto social donde se crea o en el cual se reproduce.

Normalmente, parte de la configuración de una experiencia previa que sitúa al individuo como seguidor de un estilo musical concreto, lo cual genera que se haya producido una exposición mayor a canciones de ese estilo y temática. Este modo de escucha, si bien capacita al individuo para interpretar correctamente los mensajes tanto implícitos como explícitos que se dan en el texto de la canción, requiere de mucho tiempo de análisis; por lo tanto, las canciones, en estos casos, se apartan de la distribución masiva y se destinan a un público mucho más específico.

Son muy pocos los antecedentes empíricos que podemos encontrar donde se relaciona directamente las canciones de música popular con el estudio de la violencia de género. Sin embargo, no existe ningún estudio que lo haga teniendo en cuenta diversos estilos musicales y desde una perspectiva cuantitativa, tal y como proponemos en nuestra investigación. Las aportaciones más interesantes las encontramos en el estudio de Brook, Schindler y Banning (2008), que establece un análisis de contenido cualitativo llevado a cabo sobre las letras de las cien canciones con éxito comercial seleccionadas a partir de los datos del Billboard Chart Research Services, para identificar patrones de violencia contra las mujeres.

Si bien este estudio se aproxima al tema de la violencia de género, se centra más en hacer un análisis del sexismo en la música comercial. Por otro lado, destaca el estudio de Valls, Puigvert y Duque (2008), que analiza la violencia de género entre adolescentes. En este caso, el estudio no se enfoca únicamente en la música, sino que analiza también el lenguaje de las revistas y películas destinadas a este grupo de edad. 
A nivel nacional, cabe resaltar los estudios de Berrocal y Gutiérrez (2002) o Llorens (2013). El primero establece un acercamiento interesante a la diferencia de roles que se da en la música a partir del análisis de una muestra de 13 canciones del folklore popular de las distintas Comunidades Autónomas de España. Por otro lado, con un enfoque similar, el estudio de Llorens (2013) propone el uso de las canciones dentro del ámbito educativo como una herramienta muy útil para trabajar la prevención de la violencia de género.

Muy relevantes son también las aportaciones de Gómez-Escarda y PérezRedondo (2016), que partiendo de la hipótesis de que trabajar con canciones que critican la violencia de género contra las mujeres puede favorecer una mayor empatía hacia el problema por parte de los miembros de la sociedad, plantean una estrategia metodológica original que puede ayudar a entender mejor el fenómeno, sus causas, sus tipos y sus consecuencias.

Es más habitual encontrar investigaciones que analizan la violencia de género en los videoclips de música. Desde esta perspectiva cabe resaltar el estudio de Rich et al. (1998), que posteriormente se vio completado con las aportaciones de Smith y Boyson (2006) y Kalof (2010). Si bien en estas investigaciones se hace una breve referencia al significado de las canciones, los autores centran su análisis, sobre todo, en la imagen que acompaña a la música y que proyecta un lenguaje visual muy sexista. Por último, en el estudio de Johnson, Adams y Ashburn (1995) se analiza la relación directa que se da entre el texto de las canciones y la violencia de género, pero únicamente la música rap.

\section{Objetivos y metodología}

En el marco de los antecedentes teóricos y empíricos que se han expuesto, el presente trabajo persigue la consecución de los siguientes objetivos:

1. Analizar el conjunto de las canciones que tratan el tema de la violencia de género, fomentándola o criticándola, a lo largo de las últimas décadas.

2. Establecer la relación entre los estilos musicales y la violencia de género.

3. Estudiar las fórmulas de distribución de este tipo de canciones.

4. Analizar la relación entre la duración de las canciones contra la violencia y los diferentes estilos musicales.

5. Estudiar la presencia masculina y femenina en los grupos y/o solistas que tratan esta cuestión en sus canciones con el fin de ver si el sexo influye en una mayor/menor concienciación hacia el problema. 
Para ello se ha optado por desarrollar una investigación de naturaleza cuantitativa, basada en el análisis de contenido de una muestra integrada por un total de 210 canciones relacionadas con la violencia de género, acumuladas a lo largo de casi cuatro décadas. En relación con la técnica seleccionada, se ha considerado que es la mejor herramienta para llevar a cabo una descripción cuantitativa sistemática que nos permita llegar al objetivo de la investigación (Berelson, 1952: 18); en nuestro caso: la comunicación musical.

La selección de esta muestra se obtuvo tras un exhaustivo análisis de las canciones según los criterios de ventas y distribución. Se utilizaron los informes que elaboran las dos principales agencias de gestión musical en España: Productores de Música de España (Promusicae, 2003-2016) y la Sociedad General de Autores y Editores (SGAE, 1999-2016), que indican las 50 canciones más distribuidas en España por año. Además, esta información se ha contrastado con las cifras de: Spotify, Amazon, Gran Vía Musical, i-Tunes, 7Digital y Zune (IFPI, 2006-2017).

En el marco de un muestreo estratégico intencional (Perelló, 2009), la selección de las canciones se basó en la escucha del listado de canciones más distribuidas, seleccionando para la investigación aquellos temas cuya letra estuviera en castellano, con el fin de identificar las que trataran la cuestión desde una perspectiva crítica y las que podrían fomentar y perpetuar la violencia simbólica, contribuyendo a generar un discurso y, por ende, una actitud discriminatoria hacia las mujeres, llegando a favorecer, en casos muy concretos, actitudes violentas contra ellas.

La muestra objeto de estudio se ha analizado a partir de las siguientes variables:

1. "Fomenta la violencia simbólica y/o física”. Se estudian aquellas letras que, de un modo latente o manifiesto, podrían llegar a favorecer la aparición o mantenimiento de la violencia contra las mujeres, teniendo en cuenta su relación con el resto de las variables analizadas.

2. "Denuncia la violencia". Se examinan canciones cuyos discursos critican abiertamente la violencia contra las mujeres, relacionándolas con las demás variables planteadas.

3. "Estilo". Se analizan canciones pertenecientes a los estilos que durante las últimas décadas se han distribuido más en nuestra sociedad: pop, rock, heavy metal, punk, hip hop/rap, otros (flamenco, canción española y reguetón), con el fin de observar si unos estilos se adaptan más a los textos de protesta contra la violencia hacia las mujeres que otros. Esta categorización se ha realizado a partir de las etiquetas comerciales establecidas por la industria discográfica, $y$ 
definidas tanto por Promusicae (2003-2016), como por la SGAE (1999-2016), para medir la distribución y venta de canciones por estilos musicales en España.

4. “Década”. Permite observar la evolución temporal de la temática analizada en las canciones y su adaptación a los cambios sociales. En este caso, los intervalos establecidos han sido: antes de 1980, 19801989, 1990-1999, 2000-2009 y actualmente.

5. "Puesta en escena”. Es muy importante analizar cómo entra en contacto la canción que trata sobre la violencia de género con la sociedad que la escucha. La puesta en escena condiciona la comprensión de su mensaje y facilita el uso de la canción como agente socializador. Para su mejor entendimiento, hemos dividido este aspecto en cuatro variables específicas:

5.1. "Distribución público masivo". Si la canción es distribuida entre un público mayoritario, a priori, el poder comunicativo de su mensaje será mucho mayor.

5.2. "Distribución público específico". En ocasiones, la sociedad establece una puesta en escena muy limitada para determinadas canciones que tratan sobre la violencia de género. Esto condiciona la creación de un gusto social por ese tipo de música, el cual provoca que, pese a que el mensaje sea claro y pueda tener un alto significado educativo sobre el tema, el contenido de la canción sólo llegue a un público específico y pase desapercibido para la mayoría, con lo cual se limitará su poder comunicativo.

5.3. "Formato Single". La industria musical cataloga con la etiqueta single a los contenidos musicales que se adaptan mejor a los gustos sociales del momento y que considera van a tener éxito comercial, con lo cual se favorece su distribución. El formato single representa a las canciones que más se utilizan para distribuir un estilo, un grupo/ cantante o un tema en nuestra sociedad, y que integran las principales listas de ventas.

5.4. "Formato YouTube". El portal de distribución de videos se usa para distribuir contenidos musicales apoyados por la imagen. En la última década, este portal ha tenido un éxito sin precedentes, sustituyendo a los formatos televisivos clásicos. Dicho éxito ha provocado que la industria discográfica, en general, y los grupos musicales, en particular, ocupen este portal para hacer llegar los videos oficiales de sus canciones más populares a un público masivo. 
6. “Duración”. El tiempo que dura la canción favorece la distribución y puesta en escena de determinados estilos frente a otros. Las industrias culturales fijan una duración óptima para las canciones (aproximadamente tres minutos) que favorece su distribución. En nuestro estudio se han establecido los siguientes rangos de duración: hasta 3 minutos, de 3,1 a 5 minutos y más de 5 minutos.

7. "Sexo de los miembros del grupo/solista". Al tratar la cuestión de la violencia contra las mujeres, se podría creer, a priori, que son ellas las más concienciadas y su representación en las canciones analizadas más elevada. Sin embargo, también es conocida la mayor presencia masculina en ciertos estilos. Se pretende, por tanto, comprobar la composición de los grupos/solistas a partir de los atributos siguientes: varón/es, mujer/es y ambos para contrastar si el sexo puede condicionar a la hora de transmitir el mensaje que fomenta o critica la violencia de género en las canciones.

A partir de las variables referenciadas en los párrafos precedentes, se procedió a la codificación del conjunto de las canciones que integran la muestra en tres rondas sucesivas e independientes. Este procedimiento permitió detectar errores asociados a la codificación de las variables estructurales y a posibles contradicciones en términos de la interpretación subjetiva de las variables de perfil no estructural. Con esta secuencia se ha garantizado la confiabilidad del proceso de codificación.

\section{Análisis}

Tras el análisis de la muestra objeto de estudio, se constata que en todos los estilos examinados el mayor número de canciones que tratan sobre este tipo de violencia lo hacen desde una perspectiva crítica (173). Sin embargo, también se ha identificado una cantidad importante de canciones que, lejos de denunciar la situación, más bien contribuyen a generar un discurso que podría favorecer la aparición o perpetuación de la violencia simbólica e, incluso, en algunos casos concretos, la violencia física contra las mujeres (37).

Respecto a las canciones que normalizan o favorecen la violencia -en último extremo la violencia física-, se ha podido observar que su mayor presencia se concentra en el periodo 1990-1999, y destaca la ausencia de este tipo de canciones en la actualidad. Sin embargo, sí es más habitual encontrar letras cuyo significado -latente o manifiesto- contribuye a mantener la violencia simbólica, pues en ellas se recogen ciertos estereotipos de género, que 
pueden favorecer la persistencia de la desigualdad entre mujeres y hombres en el presente (Muñoz, 2005).

Esto ratifica la tesis de que los jóvenes han crecido escuchando canciones que minimizan el papel de lo femenino en un contexto cultural, político e ideológico, donde la negación de acceso al espacio de toma de decisiones de las mujeres, la agresión en el hogar, las disparidades en el salario, el hostigamiento y la visión de la mujer como objeto en los medios son parte del día a día (Carballo, 2006: 41).

El discurso que fomenta la violencia hacia la mujer en el texto de las canciones estaba muy patente durante la década de 1980. En ese momento, en los géneros musicales más distribuidos en nuestra sociedad prevalecía el tema de la violencia contra las mujeres, contribuyendo a su normalización. Se puede observar cómo en ese periodo se mantiene el discurso machista y denigrante hacia las mujeres, tanto en aquellos estilos en los cuales tradicionalmente se había mostrado esta imagen femenina; es decir, la copla, el flamenco o la canción española (37,5\%), como en el pop (25\%), el rock (25\%) o el heavy metal (12,5\%). Sirvan de ejemplo los siguientes extractos literales:

Hoy voy a asesinarte, nena te quiero, pero no aguanto más. Hoy voy a asesinarte, nena no me volverás a engañar (Siniestro Total, "Hoy voy a asesinarte”, 1982).

Quiero verla bailar entre los muertos, la cintura morena que me volvió loco, llevo un velo de sangre en la mirada y un deseo en el alma, que jamás la encuentre. Sólo quiero que una vez algo le haga conmover. Que no la encuentre jamás o sé que la mataré. Por favor sólo quiero matarla. A punta de navaja besándola una vez más (Loquillo y los Trogloditas, "La mataré", 1987).

A medida que la sociedad va tomando conciencia de este grave problema, era de esperar que las letras que fomentaban la violencia contra las mujeres tendieran a desaparecer; pero no ha sido así en todos los estilos. Si se analizan los datos obtenidos en la primera década del siglo XXI, se encuentra que perviven estilos musicales que utilizan el mismo discurso discriminatorio hacia la mujer. A partir de la muestra objeto de estudio, se constata que más de la mitad de las canciones que pertenecen al pop mantienen estos discursos $(63,6 \%)$; mientras que, por el contrario, en el rock o en el heavy metal cada vez se percibe una sensibilización mayor.

Por otro lado, es interesante ver cómo la temática más "machista”, caracterizada en numerosas canciones de la copla o la canción popular, se ha complementado en la última época con otros géneros musicales como el reguetón. Precisamente éste se ha instalado con fuerza en nuestra sociedad como estilo musical en los años recientes, sobre todo entre el público más joven (en nuestro análisis se integra el reguetón en la categoría de otros estilos, porque según 
datos de Promusicae [2003-2016], no es sino hasta 2012 cuando se comienza a medir como estilo musical propio. Antes de esa fecha la mayoría de las canciones de reguetón se consideraba dentro del pop, quedando sólo algunos casos catalogados por la industria como reguetón). Dichas canciones, lejos de contribuir a presentar la violencia sexista como un problema a combatir, en numerosas ocasiones hacían apología de ella (36,4\% de otros estilos). He aquí algunos ejemplos:

Pa' que aprenda, $\mathrm{pa}^{\prime}$ que respete, $\mathrm{pa}^{\prime}$ que respete y pa' que aprenda ya se quede quieta y no ande de tremenda. Sale paquí sale pallá y un consejo le voy a dar eh, látigo, látigo, yo le voy a dar por atrás, por atrás, pa' que le duela otra vez. Y si ella se porta mal. Dale con el látigo. Se sigue portando mal. Dale con el látigo (Toby Toon, "Dale con el látigo", 2004).

Yo quiero hacerte el amor. Sudando, bailando yo quiero hacerte el amor. En el cuarto, yakiando, yo quiero hacerte el amor. Tú y yo, oh. Tú y yo, oh. Yo quiero hacerte el amor apretándote, pegándote... (Wisin y Yandel, "Yo quiero hacerte el amor", 2007).

En relación con la década en la que se han publicado las canciones, se puede observar (Tabla $1^{1}$ ) que tanto para el total de las canciones como para aquellas que denuncian la violencia los porcentajes más elevados se encuentran en el periodo 2000-2009. Sin embargo, en el caso de las canciones que pueden fomentar la violencia simbólica es el periodo 1990-1999 en el cual se puede hallar una mayor representación.

El hecho de que la mayoría de las canciones contra la violencia hacia las mujeres se concentre en el periodo 2000-2009 está relacionado con diferentes elementos. Sin duda, la cada vez mayor presencia de esta problemática en los medios de comunicación a partir de finales de la década de 1990 ha influido en que no sólo los medios, sino la propia sociedad y las administraciones públicas fueran más concientes de la necesidad de afrontar un problema que ya había sido planteado previamente y en toda su crudeza por las asociaciones orientadas a luchar contra la violencia y a apoyar a las víctimas.

Los Barómetros del Centro de Investigaciones Sociológicas (CIS) (2000-2017) recogen desde el año 2000 la violencia contra las mujeres en su clasificación de los principales problemas de España. El gobierno y las administraciones asumieron desde finales de 2002 la necesidad de llevar a cabo una regulación normativa expresa, estableciendo en 2003 una orden de protección a las víctimas de la violencia doméstica y promulgando en 2004 la Ley de Medidas de Protección Integral contra la Violencia de Género. Al sumar los porcentajes totales de las canciones que denuncian la violencia de género (véase Tabla 1), se puede observar que más del $80 \%$ de éstas se encuentran en el periodo 2000-2015. De este dato se puede concluir que en el

1 Todas las tablas se encuentran en el Anexo, al final del presente artículo (Nota del editor). 
siglo XXI los artistas le otorgan cada vez más importancia a la lucha contra este tipo de situaciones.

Analizando las canciones según el estilo al cual pertenecen, se puede observar en la Tabla I que la mayoría de las canciones que denuncian la violencia de género pertenecen al pop (33,9\%), seguido del heavy metal (19,5\%), el rock (18,4\%), el hip hop/rap (11,5\%), el punk (10,3\%) y, por último, otros estilos (6,3\%). Por su parte, teniendo en cuenta la década, podemos comprobar cómo en el pop se ha producido una importante evolución en las temáticas de las canciones sobre violencia contra las mujeres desde 1980 hasta la actualidad (del 25\% en la década de 1980, al 42,9\% en la actualidad); mientras tanto, en el caso del rock se ha mantenido constante (del 25\% en la década de 1980, al $25 \%$ en la actualidad).

Estos datos podrían inducirnos a pensar que este estilo musical no ha tomado una conciencia clara del problema. Sin embargo, la estabilidad en la tendencia podría deberse a la fusión de géneros que se ha dado en el país en relación con el término "rock". De este modo, esa inalterabilidad en el porcentaje del rock se vería compensado con el crecimiento del pop y la aparición de esta temática en las letras del heavy metal (del 0\% del total de los estilos en la década de 1980, al 14,3\% en la actualidad) o el punk (del $0 \%$ en la década de 1980, al 11,3\% desde el año 2000). Por otra parte, aparecen otros géneros musicales que se van desarrollando a un ritmo menor en nuestra sociedad, pero que presentan unos textos mucho más reivindicativos respecto a la denuncia del problema. Es el caso del hip hop/rap (del $0 \%$ en la década de 1980, al 10,7\% en la actualidad).

Cabe señalar que el análisis del texto de una canción es importante, pero no puede ser interpretado sin la parte musical. Cuando la letra de una canción se aísla de la música deja de transmitir el mismo significado. A lo largo de la investigación se ha podido comprobar que hay estilos musicales que se adaptan más a los textos de protesta contra la violencia de género que otros. Así, por ejemplo, las canciones del heavy metal, punk o rap tienen un lenguaje más directo a la hora de tratar la violencia contra las mujeres y enfatizan mucho más las consecuencias sociales de este problema. En estos casos, la melodía y la armonía proporcionan una especie de contexto armónico-textual, que dota de más potencia al discurso reivindicativo:

Cuento sin final, el macho a maltratar, cerdo sin San Martín, ella sin porvenir. La matarás a hostias sin piedad. Sabe la solución, mostrar debilidad. Grande en un bar, don nadie sin pegar. Cerdo machito lo que haría yo es reventar tu puta cara (Hamlet, "Muérdesela", 1998). 
Pero... ¡Pero nada! Todo el día en casa acumulando grasas y ¿no eres capaz de tener la cena preparada? Pero... ¡Calla! Pero... ¡Calla! Mira ¡no me obligues a que lo haga! Pero... ¡Calla!, te avisé, ahora habla, habla, habla, habla. Esta vez no se supo controlar, ella acaba en el hospital (El Chojín, "El final del cuento de hadas", 2005).

El rechazo o la preferencia por un determinado tipo de música condiciona mucho la percepción del discurso que está inmerso en la canción. En nuestra sociedad, la manera como se percibe la música va unida a la frecuencia auditiva de algunos géneros y a la predisposición "social" a un determinado gusto musical. De este modo, la distinta distribución de contenidos musicales influye, directamente, en la recepción del mensaje contra la violencia de género que llega al individuo. Si el mensaje va unido a un tipo de música muy distribuido (pop) llegará con más nitidez; mientras que si el mensaje va unido a un tipo de música con escasa distribución en nuestra sociedad (heavy metal, punk o hip hop/rap), puede pasar inadvertido para el público masivo, pese a que la letra de la canción podría llegar a ser una importante herramienta educativa de cara a la censura de la violencia de género. En otras ocasiones, el prejuicio que establece el oyente sobre determinados géneros sonoros no favorece en nada la transmisión ni la escucha.

En la Tabla 2 se puede comprobar que el apoyo comercial, traducido en la mayor exposición social que tiene el pop, hace que el mensaje de este tipo de canciones se distribuya de forma masiva dentro de nuestra sociedad. Por otra parte, canciones que denuncian la violencia contra las mujeres desde estilos que tradicionalmente han sido apartados del circuito comercial, sólo llegan a un público muy concreto. Así, el $94,4 \%$ de las canciones de rock, el $94,7 \%$ de las canciones de heavy metal, el $100 \%$ de las canciones punk y el 95\% de las canciones de hip hop/rap que denuncian este tipo de violencia se distribuyen a un público muy específico; mientras tanto, el $71,1 \%$ de las canciones de pop (fomentando o censurando la violencia) se distribuyen de forma masiva.

Efectivamente, la distribución de las canciones por estilos es otra variable clave, debido a la importancia que tiene en relación con el hecho de que el mensaje llegue a un público masivo o a uno específico. Para establecer esta distribución se ha tenido en cuenta el formato de presentación de las canciones según los estilos, considerando que la publicación de la canción en formato single y su acceso al video oficial a través del canal YouTube son elementos significativos de una mejor distribución del tema y favorecen una recepción masiva del mismo.

En la Tabla 3 se puede observar cómo casi las tres cuartas partes de las canciones de pop y más de la mitad de los temas que pertenecen a otros estilos 
son distribuidas de modo masivo. Además, en ambos casos más de la mitad de las canciones han sido publicadas en formato single. Respecto al pop, el $42,1 \%$ de sus videos oficiales están disponibles en YouTube, y en cuanto a otros estilos, el 31,8\%. Respecto al formato en el hip hop/rap, los singles representan un $40 \%$ de los casos y la distribución por YouTube un 35\%; mientras que en el resto de estilos el formato single presenta valores entre el $10 \%$ y el $17 \%$, y la distribución por YouTube se puede considerar más bien escasa.

El rechazo o la preferencia por un determinado tipo de música condiciona enormemente la manera en que el oyente percibe el discurso inmerso en la canción. Esto provoca que si bien en nuestra sociedad el discurso que censura la violencia contra las mujeres está muy desarrollado en la letra de las canciones en general, su influencia quede muy limitada cuando se analiza la distribución de este discurso por estilos. Así, la preferencia social y comercial hacen que el mensaje que se transmite a través de las canciones pop llegue masivamente a la sociedad; mientras que los mensajes más directos que están implícitos en estilos como el heavy metal, el punk o el hip hop/ rap pasan desapercibidos.

En muchas ocasiones los valores negativos van inmersos en géneros musicales muy escuchados y de gran éxito en nuestra sociedad. En este caso, a la hora de la recepción musical suele primar más el ritmo de la canción que el mensaje de la letra, estableciéndose una escucha más simple que oculta los valores negativos que puede llegar a transmitir la canción.

De mayor yo quiero ser mujer florero, metidita en casita yo te espero. Las zapatillas de cuadros preparadas, todo limpio y muy bien hecha la cama. De mayor quiero hacerte la comida mientras corren los niños por la casa. Y aunque poco nos vemos yo aquí siempre te espero porque yo sin ti, es que yo, es que no soy nada y quiero ser tu florero con mi cintura ancha, muy contenta cuando me das el beso de la semana... (Ella baila sola, "Mujer florero", 1997).

Te abriré las puertas del alma de par en par, dispuesta a hacer todo a tu voluntad, dispuesta a hacer todo lo que te dé la gana, qué me importa. Toda, de arriba a abajo, toda, entera y tuya, toda, aunque mi vida corra peligro, toda, de frente y de repente, toda, desesperadamente, toda, haz todo lo que sueñas conmigo... (Malú, "Toda", 2001).

Teniendo en cuenta que la mayoría de las canciones pop son distribuidas de forma masiva, en formato single y por YouTube, se podría concluir que el pop es el estilo que mayor capacidad de influencia puede tener en el público, tanto en el aspecto positivo -en la lucha contra la violencia-, como en el negativo; es decir, en la difusión de mensajes que puedan perpetuar la desigualdad entre mujeres y hombres, y, en consecuencia, la violencia contra las primeras. Asimismo, esta idea sería extrapolable a otros estilos musicales, 
pues, como se ha comprobado, casi la mitad de las canciones que pueden fomentar la violencia simbólica pertenece a esta categoría, y dentro de la misma también la mitad se distribuye de manera masiva, en formato single y, en menor medida, a través de YouTube.

La escasa distribución comercial de estilos que claramente denuncian la violencia contra las mujeres como el heavy metal, el rock, el hip hop/rap se debe a la estructura de estas canciones y, especialmente, a la duración de los temas. Estos estilos musicales apuestan, como se ha expuesto anteriormente, por un lenguaje más directo que censura la violencia de género de forma muy clara. Pero para ello también se apoyan en canciones con una mayor duración. De este modo se constata que casi el $70 \%$ del total de estos temas superan los tres minutos de duración. En géneros como el heavy metal, el $50 \%$ de las canciones superan los cinco minutos, y en el hip hop/rap sucede lo mismo con el $12,5 \%$ de los temas. Esta larga duración ocasiona que dichas canciones sean poco comerciales para la industria que prefiere distribuir temas más cortos.

Mención especial merecen en este apartado las canciones de música punk. A pesar de que éstas censuran de manera muy directa la violencia contra las mujeres y el $100 \%$ de los temas se aproximan a los tres minutos de duración -tiempo ideal exigido por la industria discográfica para favorecer su distribución-, su mensaje no se orienta al público masivo, debido a que dicho estilo utiliza formas lingüísticas consideradas "poco apropiadas" por el conjunto de la sociedad.

Tus ideas se quedaron entre ruidos de cocina. Humillada y maltratada, entregada a su capricho. De rodillas sobre el suelo, salpicada de lejía. Y esos niños engendrados, que te fueron devorando. Y maldices aquel día que aceptaste tu fracaso. Y ahora lloras en silencio, mientras esperas la muerte. ¡Madre!, ¡madre! rómpele la cara a ese cabrón.... (El Último Ke Zierre, "Madre, rómpele la cara a ese cabrón", 1993).

Su madre le edukó komo a su madre le eduko su abuela para ser una buena esposa, hay ke kallar aunke duela palizas de borratxo, insultos de matón, violaziones de gran matxo, humillaziones de un kabron... (Envidia Kotxina, "Años de amargura", 2001).

Un día Susanita le quiso echar de casa, le dijo: ¡lárgate de aquí, que te follen! Él le dio una paliza, pero ella decidida, se lo volvió a repetir, ique te follen! Volvió a decir lo mismo con mucha mala hostia según salió del hospital ique te follen! Mientras se lo decía, le dio con una estaca y le dejó llorando. ¡La hostia Susanita! debiste hacerlo antes, nadie merece estar así. Malditos gilipollas que van de puro macho y no merecen ni vivir... (La Polla, "Susanita tiene un marrón", 2003).

La música puede favorecer la construcción de identidades de género. En principio, se podría afirmar que los grupos/solistas con presencia 
exclusivamente femenina serían más proclives a interpretar canciones en las que se denuncia la violencia hacia las mujeres.

Los datos de la Tabla IV señalan que el 78,6\% de los grupos/solistas representados en la muestra están formados exclusivamente por hombres, el $16,7 \%$ por mujeres y el resto por ambos. Desde la perspectiva del estilo, las cifras más elevadas de hombres en los grupos/solistas se pueden encontrar, según este orden, en el heavy metal, el rock, el punk, el hip hop/rap, otros estilos y el pop. Se puede observar también que en todos estos estilos la casi totalidad de las canciones denuncian la violencia, tanto en los formados por hombres como por mujeres o por ambos. El pop presenta una mayor dispersión, pues los grupos o solistas masculinos representan casi la mitad de la muestra, seguidos de cerca por aquellos en los que la presencia es sólo femenina y, por último, los mixtos formados por hombres y mujeres.

Como se ha expuesto con anterioridad, a pesar de que efectivamente la mayoría de las canciones denuncian la violencia, se pueden hallar grupos/ solistas cuyas canciones pueden favorecer su surgimiento. En cuanto a otros estilos, la proporción entre hombres y mujeres es prácticamente el mismo. El hecho más relevante es que en este caso cerca de las dos terceras partes de los grupos/solistas formados por mujeres, casi la mitad de aquellos que están formados sólo por hombres y el total de los grupos integrados por ambos, presentan canciones cuyas letras pueden fomentar la violencia simbólica en contra de las mujeres.

Estos datos suponen una fiel representación de lo que ocurre en el mundo de la música. En algunos de los estilos analizados, principalmente el rock y el heavy metal, la presencia masculina ha sido una constante. Sin embargo, a pesar de que el "machismo" sigue presente en ciertos estilos, los datos evidencian, tal y como podemos ver en la tabla IV, que la concienciación de los músicos respecto a la lucha contra la violencia hacia las mujeres es cada vez mayor. El 80,6\% de canciones en el pop, el 88,2\% en el rock, 84,5\% en el heavy metal o el $100 \%$ en el hip hop o el punk demuestran que son ellos quienes más critican y denuncian estas situaciones.

Por su parte, a pesar de que en numerosas ocasiones las mujeres continúan reproduciendo en sus canciones identidades de género basadas en la lógica patriarcal, se pueden encontrar ejemplos de temas en los cuales se transmite una identidad femenina diferente, alejada de la subordinación y los clásicos estereotipos asignados a las mujeres (Viñuela 2003: 24):

Acuérdate que sé perdonar, pero soy mujer, respétame, yo vivo sola en libertad y sé perdonar, pero soy mujer, respétame, yo vivo en libertad (Mónica Naranjo, "Pantera en libertad", 1997). 
Yo no soy esa mujer, que no sale de casa y que pone a tus pies lo mejor de su alma. No me convertiré, en el eco de tu voz, en un rincón. Yo no soy esa mujer (Paulina Rubio, "Yo no soy esa mujer", 2000).

Voy a volverme como el fuego, voy a quemar tus puños de acero y del morao de mis mejillas saldrá el valor pa cobrarme las heridas. Malo, malo, malo eres, no se daña a quien se quiere no. Tonto, tonto, tonto eres no te pienses mejor que las mujeres (Bebe, "Malo", 2004).

\section{Conclusiones}

En la investigación hemos podido constatar que en los estilos musicales más difundidos en nuestra sociedad recibimos mensajes constantes en los cuales se mercantiliza el cuerpo de las mujeres, se fomenta la sumisión femenina y la superioridad masculina, y se puede llegar a impulsar la violencia de manera latente y/o manifiesta.

En cuanto a las canciones que critican la violencia contra las mujeres, se evidencia que, a lo largo del periodo analizado, su presencia en todos los estilos es cada vez mayor. Sin embargo, el tipo de lenguaje utilizado en el heavy metal, el punk o el hip hop/rap es mucho más directo, lo que en ocasiones puede provocar el rechazo de una parte de los oyentes. Los citados estilos junto con el rock se distribuyen habitualmente a un público específico y su duración suele ser mayor, excepto en el caso del punk. El pop, por el contrario, presenta una distribución masiva, tiene una presencia mayoritaria en YouTube y la duración de las canciones suele aproximarse al ideal establecido por la industria discográfica. Por tanto, se puede concluir que la capacidad socializadora del pop es mucho más elevada que la del resto de los estilos analizados.

La música presenta un importante poder divulgativo y formativo. De este modo, usar una canción conocida como material educativo ofrece una oportunidad excepcional para conectar con la realidad social y reflexionar sobre sus problemas. Cuando el oyente conoce la canción, o es seguidor del estilo musical en el cual se engloba el tema, el mensaje que se pretende transmitir llega de forma más rápida y es mayor la identificación.

Las canciones interactúan directamente con los problemas de la sociedad: los describen y analizan. Por ello, las que denuncian la violencia de género bien distribuidas y utilizadas pueden consolidar su mensaje en la generación que las recibe y las interpreta por primera vez y también en las futuras. La música se convierte así en un potente agente socializador, gracias al cual las nuevas generaciones pueden aprender valores sociales alejados de la violencia contra las mujeres. 
Esta investigación supone el comienzo de una línea de trabajo que pretende definir el papel comunicativo que tienen las canciones de la música popular en relación con su capacidad para combatir la violencia de género. Aunque parte de una muestra que integra prácticamente la totalidad de las canciones que critican la violencia contra las mujeres en los estilos musicales más difundidos en nuestra sociedad hasta la actualidad, somos conscientes de que existen otros estilos emergentes que también tratan el tema y cuya distribución es marginal hoy en día, pero que poco a poco van tomando importancia en el discurso sonoro de nuestra sociedad. Estilos como el reguetón, por ejemplo, tendrán que ser objeto de un trabajo específico, dadas sus particularidades idiomáticas. Con el fin de avanzar en este propósito, seguimos incrementado la muestra con nuevas canciones, cuyo estudio formará parte de futuros análisis.

Por otra parte, sería interesante complementar estos resultados con otros trabajos que se centren en dos aspectos fundamentales. Por un lado, en la presencia en las canciones de las diferentes fases del "ciclo de la violencia", haciendo hincapié, principalmente, en el empoderamiento de las víctimas a través de la música. Por otro, es clave avanzar en el estudio de la importancia de la música como agente de socialización, teniendo en cuenta su capacidad para orientar y/o modificar conductas, y su aplicabilidad en la prevención de la violencia contra las mujeres en el ámbito educativo.

\section{Referencias}

Alcalde, Jesús (2007), Música y comunicación, España: Fragua.

Berelson, Bernard (1952), Content Analysis in Communication Research, Estados Unidos: Hafner Press.

Berrocal, Emilio y Gutiérrez, José (2002), "Música y género: análisis de una muestra de canciones populares”, en Comunicar, núm. 18, España: Grupo Comunicar.

Brook, Bretthaver, Schindler, Tony y Banning, James (2008), "A feminist Analysis of Popular Music”, en Journal of Feminist Family Therapy, núm. 18, vol. 4, Estados Unidos: Kansas State University.

Buil, Pedro y Hormigos, Jaime (2016), "Nuevas formas de distribución de la música popular en la cultura contemporánea”, en methaodos.revista de ciencias sociales, núm. 4, vol. 1, España: methaodos.org.

Carballo, Priscila (2006), "Música y violencia simbólica”, en Revista de la Facultad de Trabajo Social UPB, núm. 22, Colombia: Universidad Pontificia Bolivariana.

CIS (Centro de Investigaciones Sociológicas) (2000-2017), Barómetros, España: Centro de Investigaciones Sociológicas.

Drösser, Christoph (2012), La seducción de la música. Los secretos de nuestro instinto musical, España: Ariel.

Gallardo, Luis y Estévez, Javier (2014), Rock y educación. Binomio para el desarrollo transversal de competencias, valores y cultura emprendedora, España: Diputación de Córdoba. 
Convergencia Revista de Ciencias Sociales, núm. 76, 2018, Universidad Autónoma del Estado de México

Giménez, Toni (1997), "El uso pedagógico de las canciones”, en Eufonía, núm. 6, España: Graó.

Gómez-Escarda, María y Pérez-Redondo, Rubén (2016), "La violencia contra las mujeres en la música: Una aproximación metodológica”, en methaodos.revista de ciencias sociales, núm. 4, vol. 1, España: methaodos.org.

Hormigos, Jaime (2008), Música y sociedad. Análisis sociológico de la cultura musical de la posmodernidad, España: Fundación Autor.

Hormigos, Jaime (2010), “La creación de identidades culturales a través del sonido", en Comunicar, núm. 34, España: Grupo Comunicar.

IFPI (2006-2017), "Global Music Report”. Disponible en: http://www.ifpi.org [22 de enero de 2017].

Johnson, James, Adams, Mike y Ashburn, Leslie (1995), "Differential gender effects of exposure to rap music on African American adolescents acceptance of teen dating violence”, en Sex Roles Journal, núm. 33, vol. 7, Estados Unidos: Springer.

Kalof, Linda (2010), "The Effects of Gender and Music Video Imagery on Sexual Attitudes", en The Journal of Social Psychology, núm. 139, vol. 3, Estados Unidos: University of Minnesota.

Levitin, Daniel (2014), El cerebro musical. Seis canciones que explican la evolución de la humanidad, España: RBA.

Lynskey, Dorian (2016), 33 revoluciones por minuto. Historia de la canción protesta, España: Malpaso.

Llorens, Ana (2013), 150 canciones para trabajar la prevención de la violencia de género en el marco educativo, España: Servicio de Educación Ayuntamiento de Valencia.

Muñoz, Paloma (2005), “Las mujeres en las músicas populares", en Convergencia. Revista de Ciencias Sociales, núm. 37, México: Universidad Autónoma del Estado de México.

Perelló, Salvador (2009), Metodología de la investigación social, España: Dykinson.

Promusicae (Productores de Música de España) (2003-2016), “Top canciones más distribuidas en España por año”. Disponible en: http://www.promusicae.es [30 de junio de 2017].

Ramírez-Hurtado, Carmen (2006), Música, lenguaje y educación. La comunicación bumana a través de la música en el proceso educativo, España: Tirant Lo Blanch.

Rich, Michael et al. (1998), "Aggressors or Victims: Gender and Race in Music Video Violence”, en Pediatrics, núm. 101, vol. 4, Estados Unidos: American Academy of Pediatrics.

Romero, Josep (2011), M de música. Del oído a la alquimia emocional, España: Alba.

SGAE (Sociedad General de Autores y Editores) (1999-2016), "Anuarios de las artes escénicas, musicales y audiovisuales”. Disponible en: http://www.anuariossgae.com [17 de febrero de 2017].

Small, Christopher (2003), Música, sociedad, educación, España: Alianza.

Smith, Stacy y Boyson, Aaron (2006), "Violence in Music Videos: Examining the Prevalence and Context of Physical Aggression", en Journal of Communication, núm. 52, vol. 1, Estados Unidos: ICA.

Valls, Rosa, Puigvert, Lidia y Duque, Elena (2008), "Gender violence among teenagers socialization and prevention”, en Violence Against Women, núm. 14, vol. 7, Estados Unidos: Sage.

Viñuela, Laura (2003), "La construcción de las identidades de género en la música popular", en Dossiers Feministes, núm. 7, España: Universitat Jaume I. 


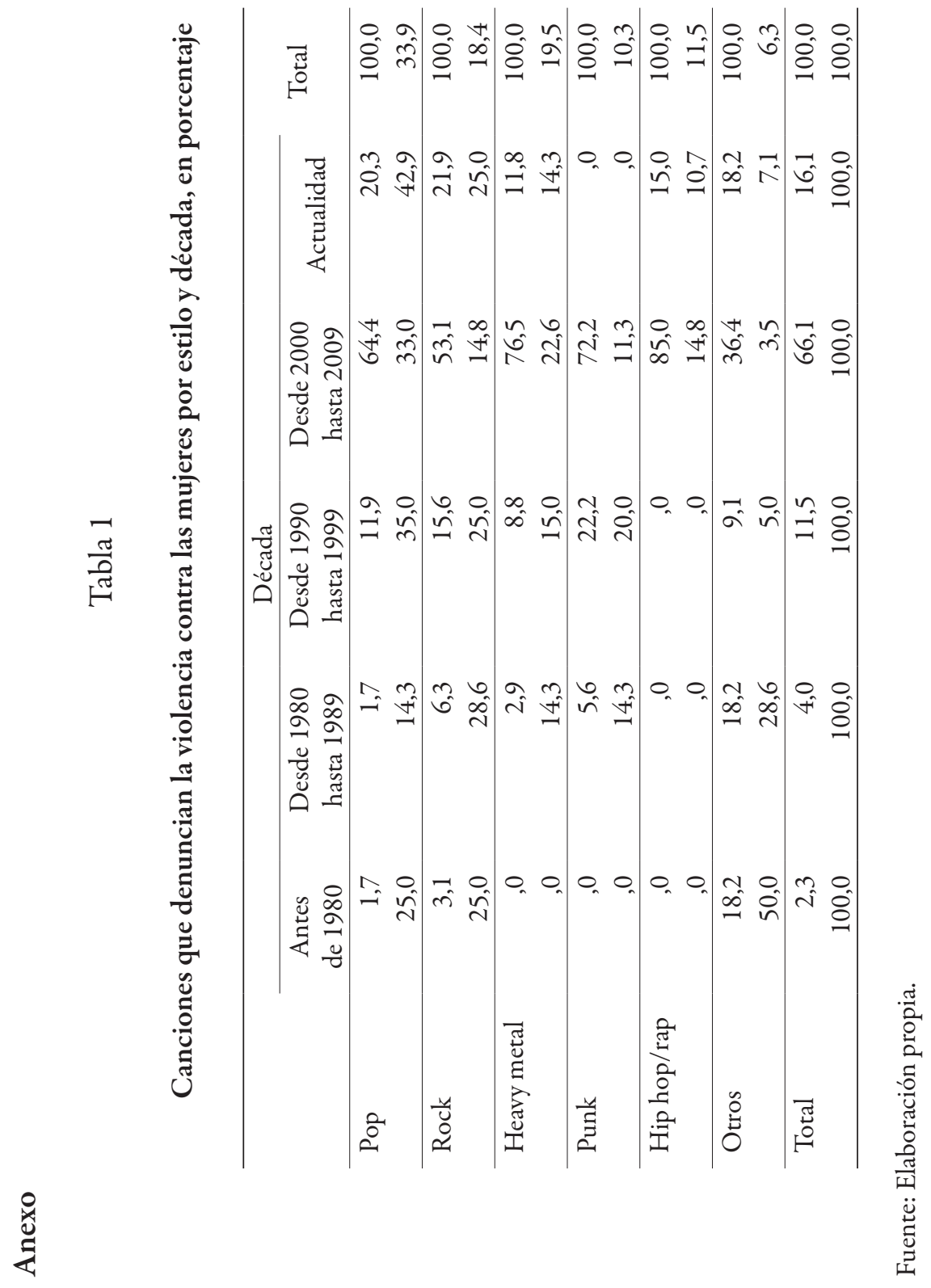




\section{Tabla 2}

Distribución de las canciones que tratan la violencia contra las mujeres por estilo y tipo de público, en porcentaje

\begin{tabular}{|c|c|c|}
\hline & \multicolumn{2}{|c|}{ Distribución público } \\
\hline & Masivo* & Específico** \\
\hline Pop & 71,1 & 28,9 \\
\hline Rock & 5,6 & 94,4 \\
\hline Heavy Metal & 5,3 & 94.7 \\
\hline Punk &, 0 & 100,0 \\
\hline Hip hop/rap & 5,0 & 95,0 \\
\hline Otros & 59,1 & 40,9 \\
\hline
\end{tabular}

Fuente: Elaboración propia.

Tabla 3

Estilos musicales y formato de las canciones, en porcentaje

\begin{tabular}{lrr}
\hline & \multicolumn{2}{c}{ Formato } \\
\cline { 2 - 3 } & Single $^{*}$ & \multicolumn{2}{c}{ YouTube } \\
\hline Pop & 53,9 & 42,1 \\
\hline Rock & 16,7 & 2,8 \\
\hline Heavy metal & 10,5 & 5,3 \\
\hline Punk & 11,1 & 11,1 \\
\hline Hip hop/rap & 40,0 & 35,0 \\
\hline Otros & 54,5 & 31,8 \\
\hline & ${ }^{*} \mathrm{c}^{2}(5, \mathrm{~N}=210)=35.854, \mathrm{p}<.001$ \\
& ${ }^{* *} \mathrm{c}^{2}(5, \mathrm{~N}=210)=33.286, \mathrm{p}<.001$
\end{tabular}

Fuente: Elaboración propia. 


\section{Tabla 4}

Fomento/denuncia de la violencia de género por estilo musical y sexo, en porcentaje

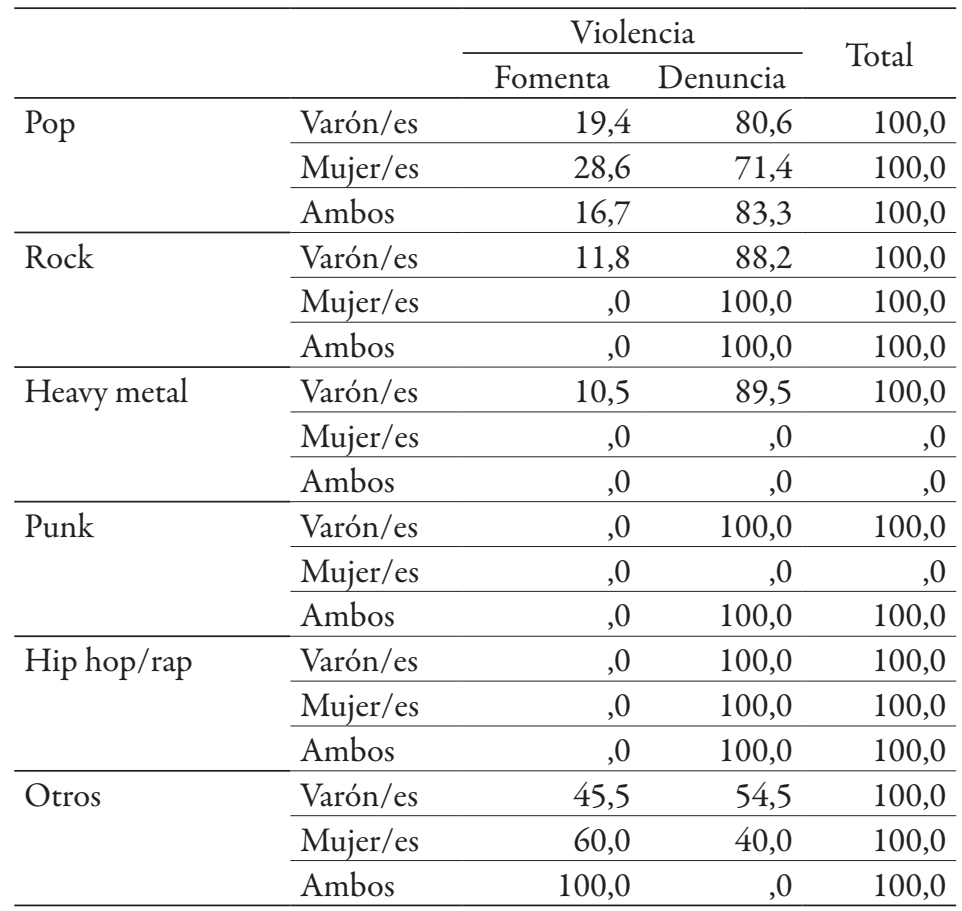

Fuente: Elaboración propia.

Jaime Hormigos-Ruiz. Doctor en Sociología por la Universidad Pontificia de Salamanca. En la actualidad es profesor de Estructura Social y Sociología de las organizaciones en la Universidad Rey Juan Carlos de Madrid, Facultad de Ciencias de la Comunicación, Departamento de Ciencias de la Comunicación y Sociología. Miembro del grupo de Investigación de Excelencia "methaodos.org". Líneas de investigación: sociología de la música, cultura, comunicación y estructura social. Publicaciones recientes: MuelaMolina, C., Perelló-Oliver, S. y Hormigos-Ruiz, J., "Unidentified advertising: Separating contents and radio owner responsibility", en European Journal of Communication, Inglaterra (2016); Perelló-Oliver, S., Muela-Molina, Cl. y Hormigos-Ruiz, J., "Publicidad ilícita, productos saludables y autorregulación", 
en Cuadernos.info, núm. 38, Chile (2016); Gómez-Escarda, M., HormigosRuiz, J. y Pérez-Redondo, R. J., "Familia y suelo pegajoso en las fuerzas armadas españolas", en Revista Mexicana de Sociología, vol. 78, núm. 2, México (2016).

María Gómez-Escarda. Doctora por la Universidad Nacional de Educación a Distancia. En la actualidad es profesora de Técnicas de Investigación Social, Sociología del Consumo y Estructura Social Contemporánea en la Universidad Rey Juan Carlos de Madrid, Facultad de Ciencias de la Comunicación, Departamento de Ciencias de la Comunicación y Sociología. Líneas de investigación: familia, género y fuerzas armadas. Publicaciones recientes: Gómez-Escarda, M. y Pérez-Redondo, R. J., "La violencia contra las mujeres en la música: Una aproximación metodológica”, en methaodos. revista de ciencias sociales, vol. 4, núm. 1, España (2016); Gómez-Escarda, M., Hormigos-Ruiz, J. y Pérez-Redondo, R. J., "Familia y suelo pegajoso en las fuerzas armadas españolas", en Revista Mexicana de Sociología, vol. 78, núm. 2, México (2016); Gómez-Escarda, M., Hormigos-Ruiz, J. y Pérez-Redondo, R. J., "Análisis sociológico de los cambios en la cultura organizativa contemporánea de las Fuerzas Armadas españolas”, en Revista Universitaria de Historia Militar, núm. 6, España (2015).

Salvador Perelló-Oliver. Doctor por la Universidad de Valencia. En la actualidad es profesor de Metodología y Técnicas de Investigación Social y Estructura Social Contemporánea en la Universidad Rey Juan Carlos de Madrid, Facultad de Ciencias de la Comunicación, Departamento de Ciencias de la Comunicación y Sociología. Es investigador principal del Grupo de Investigación de Excelencia "methaodos.org”. Líneas de investigación: metodología y técnicas avanzadas de investigación social aplicada. Publicaciones recientes: Muela-Molina, C., Perelló-Oliver, S. y Hormigos-Ruiz, J., "Unidentified advertising: Separating contents and radio owner responsibility", en European Journal of Communication, Inglaterra (2016); Perelló-Oliver, S., MuelaMolina, C. y Hormigos-Ruiz, J., "Publicidad ilícita, productos saludables y autorregulación”, en Cuadernos.info, núm. 38, Chile (2016); Muela-Molina, C. y Perelló-Oliver, S., "Advertising self-regulation. A comparative analysis between the United Kingdom and Spain”, en Comunicación y Sociedad, vol. 17, núm. 3, España (2014).

Recepción: 5 de febrero de 2017.

Aprobación: 4 de julio de 2017. 